
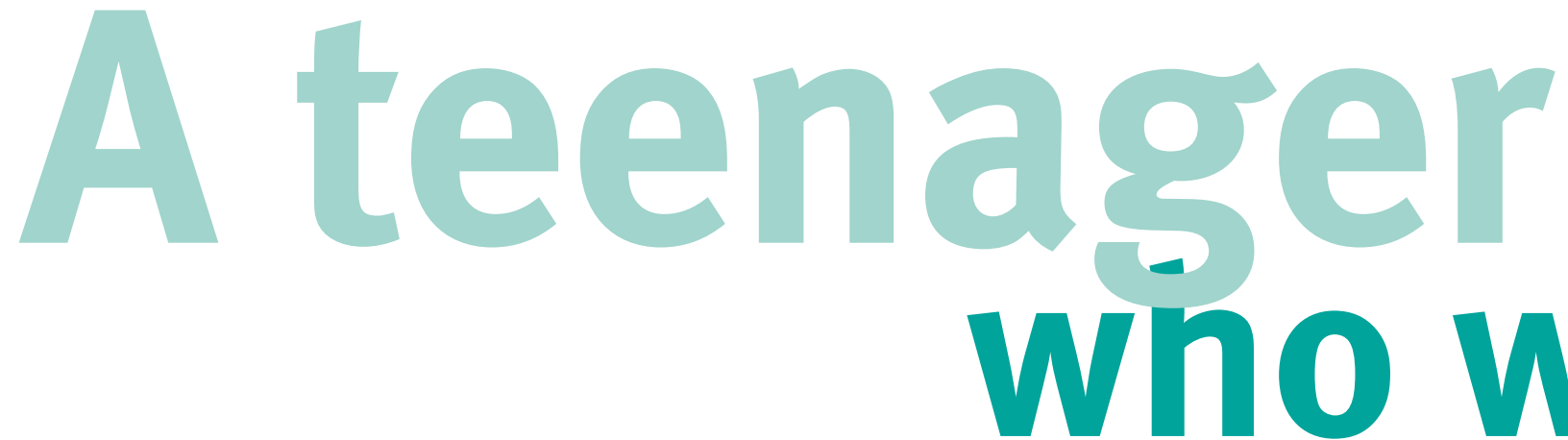

Whr
'But how is it actually done?' It was one of those conversations about euthanasia that Dutch physiciansareoften drawn into when they travel abroad. Each timethestruggle is to explain that someindividuals - or even societies - set higher valueon individual autonomy than on thesanctity of life, and al so that the issue has nothing to do with availability of palliative care or, worse, utilitarian notions. This time we were dining in the hall of an English college and my interlocutor wasan internist from another European country. 'Well', I replied, though sensing that an explanation of technicalities

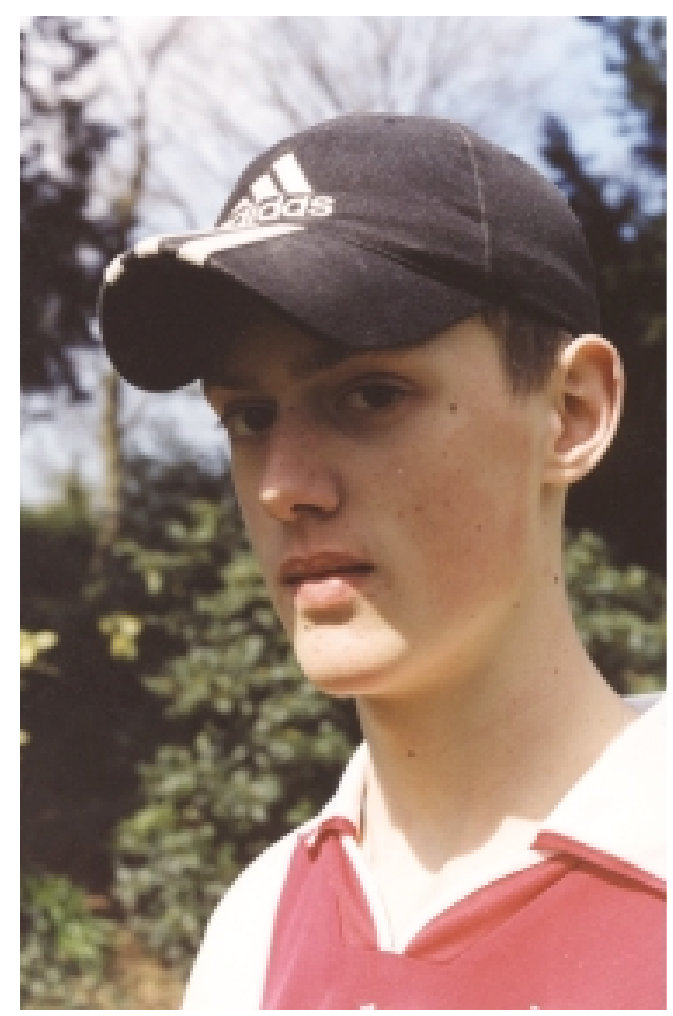

$R$, a few days after the diagnosis

(C) 2002 Blackwell Science Ltd was somehow going to rather than narrow the divide in the same way the vet does it - first an infusion of barbiturates and then of muscle face was only too obvious. He other neighbour. As the head of a university department of neurology, I had occasionally sanctioned the procedure - four times in 18 years - but had never performed it myself. On each occasion the central issue had been loss of dignity, not pain. All the patients had been elderly. Then I met R. It all started on a Saturday morning, when a fresh resident and I weretak- ing over from the team that had been on call the previous night. The last reported item was a telephone call that had just come in from a family practitioner, about a 16-year-old boy with a glioblastoma who had tried to cut his wrist. About an hour later the resident phoned me from the Accident and Emergency department. Thewound wasonly superficial (inflicted on the right wrist with his nondominant but stronger left hand), but apparently the patient, as well as his family, were in great distress. The illness had begun 6 months before, when $R$ had gone on a trip abroad with his school class, despite a recent, continuous headache. In Berlin he had been admitted to hospital because of vomiting and right-sided weakness. MR scanning showed a tumour and a biopsy - performed after hisreturn home- confirmed the diagnosis of malignant glioma. Radiation therapy and dexamethasone resulted in some improvement, which enabled him to return to school and to enjoy a journey to the USA with his parents and two older sisters. One month beforeadmission the headacheand right-sided weakness again worsened; the scan had shown tumour recurrence. Treatment with a new chemotherapeutic agent was then offered, and was eventually started 2 days beforethe present crisis. At that moment $\mathrm{R}$ refused all drugs and said that heonly wanted to die. I agreed with the resident's proposal to admithim because of the tense situation and promised that I would talk to him on the ward.

When I entered R's room, with one of the nurses, I felt utterly confident that this suicide attempt resulted from temporary despair and that it would be relatively simple to persuadethe patient and his family that life still had much to 

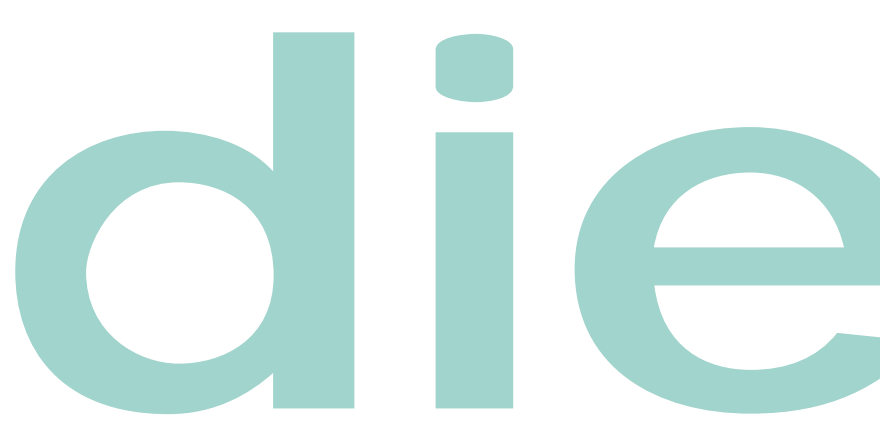

\section{ETHICAL ISSUES}

offer him. When I left theroom, threequarters of an hour later, it was me who had been convinced - by a dysphasic patient and the united front of hisparentsand sisters. Atfirst it had been difficult to recognize $R$, with his Cushingoid shape and sparsehair, astheheal thyyoung boy hemusthave been not so long ago. Hewas sitting on hisbed, in tears, whiletheeldest sister continuously stroked his arm. It turned out that he had been her pet ever since he was a baby. Conversation with $R$ was halting because he could understand and utter only simple sentences, but he was adamant in his responses once he had understood me; sometimeshisfamily offered a correct interpretation of what hewastrying to say. Thepicturethat began to form itself was that of an easygoing but taciturn and determined boy, who loved soccer and other sports and who had planned to train as a policeman as soon ashehad finished secondary school. In hispresent statehewasnot only unable to walk, but also, for thelast few days, hehad increasing difficulties with speaking, reading, writing and even with understanding video films. All he could do was to think, especially about all the simpleactivities of life that were no longer open to him. In fact hehad wanted to dieever sincethe tumour recurrence had been diagnosed, 3 weeks before. He had confessed this only that same morning. Yes, he did have headache, but no, he did not want higher doses of analgesics or sedative drugs. His present state was the opposite of what hehad al ways wanted to be. It had to stop, it had to stop immediately.

At theend of thisfirst conversation I told him I was now on his side, but that a single person could not take decisions of such importance and that the procedure usually takes several days. He made clear that this was unacceptable.
I came back that evening and found him as determined as beforein hiswish to die. I arranged consultations for the next day (Sunday) by the neurologist who had seen him as an outpatient, by the psychiatrist, and finally by an independent internist. $R$ made sure he left no doubt in any of them about his wish, notwithstanding his language handicap. I met separately with all the nurses on duty; most could understand R's request, but few wereprepared to act on it. Then followed another string of telephonecalls, to the family physician, thedirector of thehospital, the coroner and, lastly, to the pharmacy.

That Sundayevening oneof thenurses, whose shift had ended at 4 pm, cameback at 8. Together we went to collect and preparethe drugs. On entering R's room for the last timel was briefly unsettled to find him lying down in full regalia, that is, in the shirt of his favourite soccer team. He was now quiet, and wore a contented smile. We sat down for a few minutes with him and his family to make sure that his wishes were unchanged and to explain how the end would come. Before I opened the valve on the intravenous line we made sure they were all as close together asthey wished. When R's eyelidsfinally closed he had a parent at each cheek and held a sister with each hand.

Would this story soften the critical colleague who probably decided that hewould never again sit next to meat dinner? I doubt it. But I think I have done something for R. At least that is what hisparentsand sisterstold mewhen wemet once more, a few weeks later.

The picture was supplied by the patient's parents and sisters who also havegiven their full approval of text.

\section{J . van Gijn}

University Department of Neurology, Utrecht, Heiderberglaan 100 , NL-3584 CX Utrecht, the Netherlands; email: J .vanGijn@neuro.azu.nl Practical Neurology, 2002, 2, 362-363 